Check for updates

Cite this: RSC Adv., 2018, 8, 32893

\title{
A gold nanoparticle based colorimetric and fluorescent dual-channel probe for acetylcholinesterase detection and inhibitor screening $\dagger$
}

\begin{abstract}
Jie Lv, Binnan He, Na Wang, Meng Li $\mathbb{D}$ * and Yulong Lin*
Based on the competitive host-guest interaction between $p$-sulfonatocalix[6]arene $\left(p-\mathrm{SC}_{6} \mathrm{~A}\right)$ capped AuNPs and Rhodamine B (RhB)/acetylthiocholine, a fluorescent and colorimetric dual channel probe was developed for rapid detection of AChE with high sensitivity and selectivity. The detection limit was estimated to be $0.16 \mathrm{mU} \mathrm{mL}{ }^{-1}$. Crucially, due to the specific host-guest interaction, the high selectivity of the bioassay permitted the discrimination of AChE from other cations and proteins including biothiols and enzymes. Furthermore, the present method was also successfully applied to determinate AChE levels and screen AChE inhibitors in real cerebrospinal fluid (CSF) samples, which suggested that our proposed method has great potential to be applied in monitoring the disease progression and drug treatment effects of Alzheimer's disease (AD).
\end{abstract}

Received 21st July 2018

Accepted 17th September 2018

DOI: $10.1039 / \mathrm{c} 8 \mathrm{ra06165c}$

rsc.li/rsc-advances

Due to the distinctive physical and optical properties, gold

\section{Introduction}

Acetylcholine (ACh), as a central neurotransmitter, plays a decisive role in memory and learning. ${ }^{1,2}$ It has been reported that Alzheimer's disease (AD), the most common form of dementia in elderly people, is related to a low level of ACh in the brain. ${ }^{3,4}$ The hydrolysis of ACh catalyzed by acetylcholinesterase (AChE) at cholinergic synapses can cause the termination of synaptic transmission. Furthermore, much research has provided evidence that AChE can also accelerate the aggregation of amyloid- $\beta$ peptide making a further contribution to the progression of $\mathrm{AD}^{5-7}$ Therefore, sensitive and quantitative detection of AChE activity and screening of its inhibitors are of diagnostic importance and have therapeutic implications.

To this end, a range of methods/techniques for detection of AChE level have been employed, including the colorimetric Ellman method ${ }^{8,9}$ or the detection of hydrogen peroxide $\left(\mathrm{H}_{2} \mathrm{O}_{2}\right)$ produced by oxidation of choline. ${ }^{10,11}$ With the development of $\mathrm{H}_{2} \mathrm{O}_{2}$ sensors, ${ }^{12-14}$ recently, fluorescent or colorimetric approaches based on synthetic probes and nanozymes, ${ }^{15-18}$ as well as various electrochemical methods, ${ }^{19,20}$ have been developed to monitor AChE activity and screen the inhibitors of AChE. However, most of these methods cannot discriminate AChE from other biothiols. The poor sensitivity and low specificity make them unsuitable for biological sample analysis.

College of Pharmaceutical Sciences, Hebei Medical University, Shijiazhuang, 050017, China. E-mail: limeng87@hotmail.com; linyulong8@163.com; Fax: +86 31186266901; Tel: +86 311-86266901

$\dagger$ Electronic supplementary information (ESI) available. See DOI: 10.1039/c8ra06165c nanoparticles (AuNPs) have been successfully employed as a colorimetric probe for the detection of AChE activity based on their size-dependent surface plasmon resonance absorption. ${ }^{21-23}$ Although promising, the aggregation of AuNPs in most of these methods was caused by salt-sensitive electrostatic interaction. The electrostatic interaction is not stable in physiological environment, since some biomacromolecules in vivo might also compete for the interactions with the molecules on the surface of nanoparticles. Supramolecular host-guest interaction has played an important role in the chemical sensing research, including the sensor chip for the metal ion detection $^{24,25}$ and the fluorescent DNA detection. ${ }^{26,27}$ The use of hostguest interactions is an attractive alternative to electrostatic interaction since the recognition motifs are specific and bioorthogonal without an additional catalyst, which is suitable for biological application.

Herein, a new dual-signalling sensing strategy based on the competitive host-guest interaction between $p$-sulfonatocalix[6] arene $\left(p-\mathrm{SC}_{6} \mathrm{~A}\right)$ capped AuNPs and reporting probe/target was developed. Rhodamine B (RhB) and acetylthiocholine (ATC, an analogue of ACh) were used in a model system as the probe and target molecule, respectively. RhB is an ideal reporter for this assay owing to its water solubility and high fluorescence quantum yield. Especially, $\mathrm{RhB}$ has the suitable binding affinity with $\mathrm{SC}_{6} \mathrm{~A}$, which is weaker than ATC but stronger than other numerous biologically abundant cations, leading to the assay with maximized sensitivity and minimized interference by nontargeted species. ${ }^{28}$ Free $\mathrm{RhB}$ is highly fluorescent in aqueous solution, however, it displays strong fluorescence quenching 


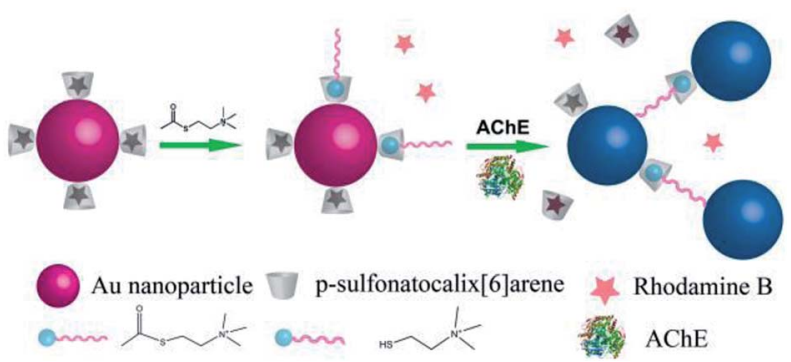

Fig. 1 System for detection of AChE activity based on RhB-p-SC ${ }_{6} A-$ AuNPs aggregation and $\mathrm{RhB}$ release induced by the competitive hostguest interaction between $p-\mathrm{SC}_{6} \mathrm{~A}-\mathrm{AuNPs}$ and $\mathrm{RhB}$ /quaternary ammonium group.

when interacting with $p-\mathrm{SC}_{6} \mathrm{~A}$. More importantly, through binding with $p$ - $\mathrm{SC}_{6} \mathrm{~A}$, the $\mathrm{RhB}$ molecules are closely associated with AuNPs which would enhance the quenching efficiency of $\mathrm{RhB}$. Upon addition of ATC into the $\mathrm{RhB}-p$ - $\mathrm{SC}_{6} \mathrm{~A}$-AuNPs solution, the $\mathrm{RhB}$ molecules existed inside the $p-\mathrm{SC}_{6} \mathrm{~A}$ host can be replaced by ATC, leading to the recovery of the fluorescence. When AChE was introduced, ATC could be hydrolyzed by AChE to generate thiocholine. Thiocholine strongly binds onto surfaces of AuNPs via the formation of Au-S bond. At the same time, the quaternary ammonium group on thiocholine and the $p$ - $\mathrm{SC}_{6} \mathrm{~A}$ molecules attached on different AuNP surfaces may be able to interact via host-guest interaction and cause the aggregation of AuNPs and a release of $\mathrm{RhB}-p-\mathrm{SC}_{6} \mathrm{~A}$, leading to a further recovery of $\mathrm{RhB}$ fluorescence. With the two types of reporters, the system can differentiate well between thiocholine and other biothiols and overcome the interference of salts effects, making it suitable for monitoring the level of AChE in the cerebrospinal fluid (CSF), which is relevant to the progression of $\mathrm{AD}$ (Fig. 1)..$^{3-7}$

\section{Experimental}

\section{Materials and measurements}

Gold(III) chloride trihydrate $\left(\mathrm{HAuCl}_{4} \cdot 3 \mathrm{H}_{2} \mathrm{O}\right)$, Rhodamine B (RhB), sodium borohydride $\left(\mathrm{NaBH}_{4}\right)$, acetylcholinesterase (AChE), chymotrypsin and glucose oxidase were obtained from Sigma-Aldrich. para-Sulfonatocalix[6]arene $\left(p-\mathrm{SC}_{6} \mathrm{~A}\right)$ was purchased from TCI Development Co., Ltd. (Shanghai, China). Arginine, glutamic acid, tyrosine and threonine were obtained from Aladdin Reagent Inc. (China). All these reagents were used as received without further purification. Deionized water (18.2 $\mathrm{M} \Omega \mathrm{cm}$ ) used for all experiments was obtained from a Milli-Q system (Millipore, Bedford, MA).

A JASCO FP-6500 spectrofluorometer was used to monitor the fluorescence of RhB. The slit width for the excitation and emission was $5 \mathrm{~nm}$. The UV-vis absorption spectra of $\mathrm{Au}$ nanoparticles were recorded by a Jasco-V550 UV-vis spectrophotometer. Fourier transform infrared spectroscopy (FTIR) measurements were carried out with a BRUKER Vertex 70 FTIR spectrometer. The sample was prepared as pellets using spectroscopic grade $\mathrm{KBr}$. Transmission electron microscopic (TEM) experiments were performed on a Philips Tecnai G2 20 S-TWIN microscope operating at $200 \mathrm{kV}$.

\section{Synthesis of $\boldsymbol{p}$ - $\mathrm{SC}_{6} \mathrm{~A}$ capped AuNPs}

The $p-\mathrm{SC}_{6} \mathrm{~A}$-AuNPs were synthesized according to previous reports. ${ }^{29}$ Briefly, $p$-SC $\mathrm{SC}_{6} \mathrm{~A}$ solution $(2 \mathrm{~mL}, 10 \mathrm{mM})$ was mixed with deionized water $(94 \mathrm{~mL})$ under mid stirring at room temperature, and then $\mathrm{HAuCl}_{4}$ solution $(2 \mathrm{~mL}, 26.3 \mathrm{mM})$ was added. After stirring for $20 \mathrm{~min}$ in the dark, freshly prepared $\mathrm{NaBH}_{4}$ solution $(2 \mathrm{~mL}, 10 \mathrm{mM})$ was added into the above mixture solution immediately, and then the reaction was allowed to proceed for $2 \mathrm{~h}$ in the dark. The obtained $p$-SC $\mathrm{S}_{6} \mathrm{~A}$-AuNPs were washed twice by centrifugation to remove the free $p-\mathrm{SC}_{6} \mathrm{~A}$. After that, $p$ - $\mathrm{SC}_{6} \mathrm{~A}$-AuNPs were dispersed in deionized water and stored at $4{ }^{\circ} \mathrm{C}$ for further use.

\section{Synthesis of RhB-p-SC ${ }_{6} \mathrm{~A}-\mathrm{AuNPs}$}

$\mathrm{RhB}(9.58 \mathrm{mg})$ was dissolved in deionized water $(10 \mathrm{~mL})$ to obtain the stock solution. Then different amounts of RhB stock solution were added respectively into the solutions of $p-\mathrm{SC}_{6} \mathrm{~A}-$ AuNPs (5.5 nM) under stirring. The mixture was stirred continuously at room temperature for $2 \mathrm{~h}$. After that, the fluorescence spectra of the mixture solutions were monitored with excitation at $550 \mathrm{~nm}$. As the concentration of RhB increased, the florescence of the resulting solution was intensified. In a low concentration region $(c=0-2 \mu \mathrm{M})$, the very weak fluorescence observed in $\mathrm{RhB}-p-\mathrm{SC}_{6} \mathrm{~A}$-AuNPs solutions, indicating that almost all the $\mathrm{RhB}$ molecules interacted with $p-\mathrm{SC}_{6} \mathrm{~A}$ on the surface of AuNPs. However, the emission intensity increased when the concentration of $\mathrm{RhB}$ was greater than $2 \mu \mathrm{M}$. Therefore, we chose $2 \mu \mathrm{M}$ as the optimal concentration of RhB to synthesize RhB- $p$-SC $\mathrm{SC}_{6} \mathrm{~A}$-AuNPs.

\section{Detection of AChE activity assay}

For the sensitivity of this assay, different levels of AChE were added to the PBS solution (10 mM, $\mathrm{pH}=8.0)$ composed of ATC $(20 \mu \mathrm{M})$ and $\mathrm{RhB}-p$-SC $\mathrm{SC}_{6} \mathrm{~A}$-AuNPs (5 nM), followed by incubation at room temperature for $20 \mathrm{~min}$ to make the reaction between AChE and ATC sufficiently. After that the absorption spectra and fluorescence spectra were monitored. For the selectivity of this assay, different biothiols, amino acids (final concentration of each biothiol or amino acid was $0.1 \mathrm{mM}$ ) or enzymes (final concentration of each enzyme was $1 \mathrm{U} \mathrm{mL}^{-1}$ ) instead of AChE were added to the mixture of RhB- $p$-SC $\mathrm{S}_{6} \mathrm{~A}$-AuNPs and ATC, respectively. The mixtures were incubated at room temperature for $20 \mathrm{~min}$, and then their absorption spectra and fluorescence spectra were recorded.

\section{Evaluation for inhibitor assay}

For the inhibition assay, different concentrations of tacrine (an approved AChE inhibitor) were first premixed with AChE (50 $\mathrm{mU} \mathrm{mL} \mathrm{m}^{-1}$ ) for $30 \mathrm{~min}$ at $37{ }^{\circ} \mathrm{C}$. Then, the pretreated $\mathrm{AChE}$ samples (The final concentration of AChE was $5 \mathrm{mU} \mathrm{mL}^{-1}$ ) were mixed with RhB-p-SC ${ }_{6} \mathrm{~A}-\mathrm{AuNPs}$ and ATC. Finally, the reaction solution was allowed to stand at room temperature for $20 \mathrm{~min}$. The absorbance of each sample was recorded using UV-vis spectroscopy. The inhibitory ratios (\%) of tacrine was expressed as follows: 


$$
\text { Inhibitory ratio }(\%)=\frac{A_{600}^{\mathrm{E} 0} / A_{520}^{\mathrm{E} 0}-A_{600} / A_{520}}{A_{600}^{\mathrm{E} 0} / A_{520}^{\mathrm{E} 0}-A_{600}^{0} / A_{520}^{0}} \times 100
$$

where $A_{600} / A_{520}$ was the ratio of the absorbance value at $600 \mathrm{~nm}$ to that at $520 \mathrm{~nm}$ in the presence of both the inhibitor and the enzyme, $A_{600}^{\mathrm{EO}} / A_{520}^{\mathrm{EO}}$ was the ratio of the absorbance value at $600 \mathrm{~nm}$ to that at $520 \mathrm{~nm}$ with enzyme only. And $A_{600}^{0} / A_{520}^{0}$ was the ratio of the absorbance value at $600 \mathrm{~nm}$ to that at $520 \mathrm{~nm}$ in the absence of the enzyme and inhibitor. The fluorescence of the system was also monitored, and the inhibitory ratio was calculated with the same method.

\section{Handing of mice}

Eight-week-old male C57BL6/J mice with body weights between 20 and $25 \mathrm{~g}$ were obtained from the Experimental Animal Center of the Chinese Academy of Medical Sciences. All the protocols and procedures for animal handling were carried out following the guidelines of the Hebei committee for care and use of laboratory animals, and were approved by the Animal Experimentation Ethics Committee of the Hebei Medical University. CSF was collected under anaesthesia using a glass pulled micropipette after exposure of the cisterna magna, taking care not to contaminate the CSF with blood. The CSF was immediately diluted 1:10 in phosphate buffered saline (PBS) and detected in one day after collection.

\section{Results and discussion}

\section{Synthesis and characterization of the RhB-p-SC ${ }_{6} \mathrm{~A}-\mathrm{AuNPs}$}

To develop this strategy, we first synthesized $\mathrm{SC}_{6} \mathrm{~A}$ modified AuNPs using $\mathrm{SC}_{6} \mathrm{~A}$ as the stabilizer. $p$-SC $\mathrm{SC}_{6} \mathrm{~A}$-AuNPs were monodispersed with average size of $\sim 13 \mathrm{~nm}$ according to transmission electron microscopy (TEM) characterization (Fig. S1A $\dagger$ ). The $p$-SC $\mathrm{S}_{6} \mathrm{~A}-\mathrm{AuNPs}$ solution showed typical plasmon absorption around $520 \mathrm{~nm}$ (Fig. $\mathrm{S} 2 \dagger$ ). The modification of $p-\mathrm{SC}_{6} \mathrm{~A}$ on the surface of AuNPs was evidenced by FTIR. As shown in Fig. S3, $\dagger$ the characteristic absorption peaks of $\mathrm{SO}_{3}{ }^{-}$at $1177 \mathrm{~cm}^{-1}$ and $1113 \mathrm{~cm}^{-1}$ found in pure $p-\mathrm{SC}_{6} \mathrm{~A}$, were shifted to $1155 \mathrm{~cm}^{-1}$ and $1104 \mathrm{~cm}^{-1}$, respectively, which suggested that the $\mathrm{SO}_{3}{ }^{-}$groups grafted onto the surface of AuNPs. ${ }^{29} \mathrm{RhB}-p-\mathrm{SC}_{6} \mathrm{~A}$-AuNPs were prepared by mixing various concentrations of $\mathrm{RhB}(0-4 \mu \mathrm{M})$ with $p$-SC ${ }_{6} \mathrm{~A}$-AuNPs $(5.5 \mathrm{nM})$ solution under mild stirring. To identify an optimal concentration of RhB that could be appended to $p$-SC 6 A-AuNPs, the fluorescence of the $\mathrm{RhB}-p-\mathrm{SC}_{6} \mathrm{~A}$ AuNPs solutions were monitored after equilibration for $2 \mathrm{~h}$. As shown in Fig. S4, $\uparrow$ the optimal concentration of RhB would be $2 \mu \mathrm{M}$, when no excess RhB was free in the solution and only very weak fluorescence was observed. Furthermore, complexed with RhB could not change the absorption band of $p-\mathrm{SC}_{6} \mathrm{~A}$ AuNPs indicating no aggregation occurred during the functionalized procedure which was in accordance with the TEM image (Fig. S2 and S1B $\dagger$ ).

\section{Quantitative detection of ATC by RhB- $p$-SC SCA-AuNPs $\mathrm{A}$}

To evaluate the sensing ability of RhB- $p$-SC $\mathrm{C}_{6} \mathrm{~A}-\mathrm{AuNPs}$ for ATC, the absorbance and fluorescence spectra of $\mathrm{RhB}^{-} p-\mathrm{SC}_{6} \mathrm{~A}-\mathrm{AuNPS}$
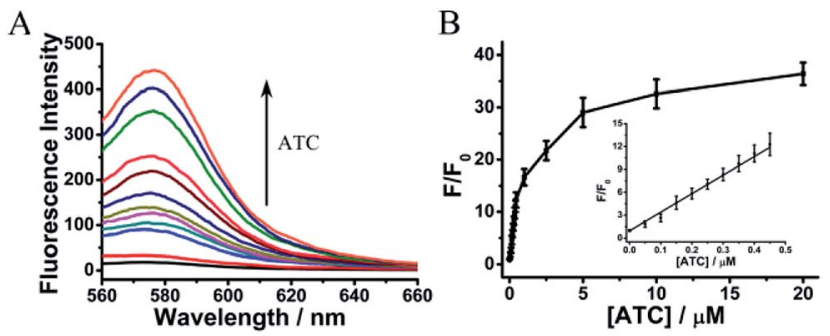

Fig. 2 The sensitivity of this assay for detection of ATC by the release of RhB. (A) The fluorescence emission spectra of RhB-p-SC ${ }_{6} A-A u N P s$ that were incubated with different concentrations of ATC. (B) The relationship between $F / F_{0}$ and the concentration of ATC from 0 to 20 $\mu \mathrm{M}$. Error bars were estimated from three independent measurements. Inset was a linear region. $F$ and $F_{0}$ were the fluorescence intensities of RhB- $p$-SC 6 A-AuNPs at $578 \mathrm{~nm}$ in the presence and absence of ATC, respectively. The excitation wavelength was $550 \mathrm{~nm}$.

in the presence of ATC were monitored (Fig. 2). Addition of ATC to the solution of AuNPs did not induce absorption spectral variation (Fig. $\mathrm{S} 2 \dagger$ ) but caused the release of $\mathrm{RhB}$ to recover its fluorescence. The detection range of ATC was from 0.05 to 20 $\mu \mathrm{M}$ (Fig. 2B) and the linear relationship between corresponding fluorescence change $\left(F / F_{0}\right)$ and ATC concentration was shown in Fig. 2B. The detection limit for ATC can be as low as $13 \mathrm{nM}$, which attributed to the sensitivity of this assay to detect AChE.

\section{Sensitivity of the assay for AChE detection}

AChE can catalyze its substrate ATC to generate thiocholine, which would lead to the aggregation of $p$-SC 6 A-AuNPs. For further determining the sensitivity of the protocol to monitor the activity of AChE, we first applied the AuNP-based colorimetric assay. Various amounts of AChE were added to the solution composed of ATC $(20 \mu \mathrm{M})$ and RhB- $p$-SC ${ }_{6} \mathrm{~A}$-AuNPs $(5$ $\mathrm{nM})$ in PBS (10 mM, pH = 8.0), followed by incubation at room temperature for $20 \mathrm{~min}$ to make the reaction between AChE and ATC sufficiently. The aggregation process of AuNPs can be easily visualized by a colour change from red to purple with the nakedeye (Fig. 3A). Simultaneously, the UV/vis absorption spectra of the solutions were recorded. As indicated in Fig. 3A, as the concentration of AChE increased, the absorption around $520 \mathrm{~nm}$ gradually decreased along with an increase in intensity of the band above $600 \mathrm{~nm}$ (Fig. 3A), indicating the formation of AuNP aggregates. The aggregation process was also directly confirmed by TEM analysis (Fig. S5 $\dagger$ ).

It is worth noting that, at low AChE concentrations (0-5.0 $\mathrm{mU} \mathrm{mL}{ }^{-1}$ ), the plot of $A_{600} / A_{520}$ (the ratio of absorbance at $600 \mathrm{~nm}$ and $520 \mathrm{~nm}$ ) versus the concentrations of AChE revealed a nearly linear relationship. The limit of detection of this assay was evaluated to be $0.46 \mathrm{mU} \mathrm{mL}^{-1}$, which, to our knowledge, was much lower than most of the previous reported optical methods. ${ }^{22,23}$ The high sensitivity of our assay was raised from the specific host-guest interactions between the quaternary ammonium group on thiocholine and the $p-\mathrm{SC}_{6} \mathrm{~A}$ molecules attached on different AuNP surfaces. The lowest detectable concentration of AChE was further determined via the fluorescence recovery of $\mathrm{RhB}$. As shown in Fig. 3E, the emission intensity enhancement rate $\left(F / F_{0}\right)$ was fast at low AChE 

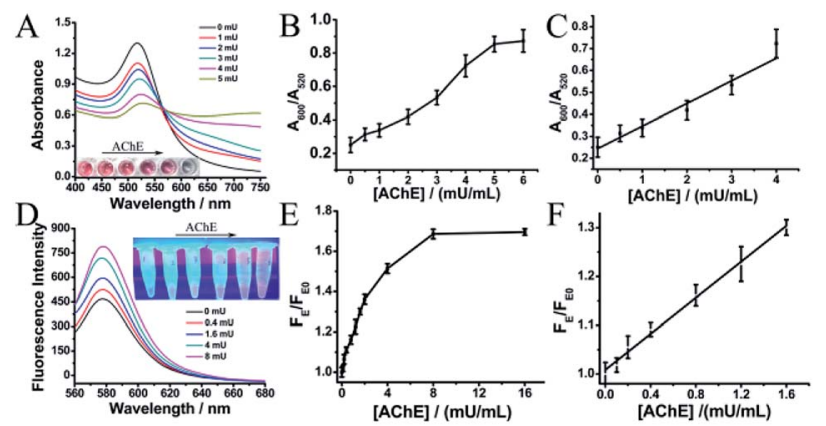

Fig. 3 The sensitivity of this assay for AChE activity by colorimetric and fluorescent methods. (A) Absorbance spectra of RhB-p-SC ${ }_{6} A-A u N P s$ that were incubated with different concentrations of $A C h E$ in the presence of ATC $(20 \mu \mathrm{M})$. Inset were the photographs of corresponding solutions. (B) Variation of $A_{600} / A_{520}$ versus the concentration of $\mathrm{AChE}$ for the solution of RhB-p-SC ${ }_{6} \mathrm{~A}$-AuNPs containing ATC (20 $\mu M)$. (C) The liner region of (B). (D) The fluorescence emission spectra of $\mathrm{RhB}$ from $\mathrm{RhB}-p-\mathrm{SC}_{6} \mathrm{~A}-\mathrm{AuNPs}$ by incubating with various concentrations of AChE in the presence of ATC $(20 \mu \mathrm{M})$. Inset were the fluorescent images. (E) Calibration curve corresponding to $F_{\mathrm{E}} / F_{\mathrm{EO}}$ against the concentration of $A C h E$ from fluorescent assay. $(F)$ The liner region of $(E) . F_{E}$ and $F_{E O}$ were the fluorescence intensities of RhB-p$\mathrm{SC}_{6} \mathrm{~A}$-AuNPs containing ATC $(20 \mu \mathrm{M})$ at $578 \mathrm{~nm}$ in the presence and absence of $A C h E$, respectively.

concentrations and became slower when the concentration was greater than $2 \mathrm{mU}$. The detection limit can be as low as $0.16 \mathrm{mU}$ $\mathrm{mL}^{-1}$ via the fluorescence recovery of RhB, which was comparable to that of recently reported assays for AChE. ${ }^{17-19}$

\section{Selectivity of the assay for AChE detection}

To evaluate the specificity of this assay for AChE, we next measured the interference from other biothiols, amino acids, anions, cations or proteins especially those that were found abundantly in human body. With thiol group, biothiols, such as cysteine (Cys) and glutathione (GSH), could readily attach on the surfaces of AuNPs via Au-S bonds, which were quite similar to thiocholine. However, these biothiols even at high concentrations could not recovery the fluorescence of the dye because of the relative high binding affinity of $p-\mathrm{SC}_{6} \mathrm{~A}$ to $\mathrm{RhB}$ (Fig. $\mathrm{S} 6 \dagger$ ). Furthermore, owing to the lacking of the positively charged quaternary ammonium group which could interact with $p-\mathrm{SC}_{6} \mathrm{~A}$ on the surface of AuNPs, they were also unable to induce the aggregation of AuNPs (Fig. 4A). Several other enzymes, proteins or amino acids such as bovine serum albumin (BSA), chymotrypsin, glucose oxidase, arginine, glutamic acid, tyrosine and threonine were also employed to evaluate the selectivity of the sensor for AChE. As shown in Fig. S7 $\uparrow$ and $4 \mathrm{~B}$, for other amino acids or proteins with a concentration up to 100 times higher than that of AChE, the $A_{600} / A_{520}$ was almost unchanged compared with the control group, indicating that our assay displayed a high selectivity for AChE.

\section{Evaluation for inhibitor assay}

Encouraged by the sensitivity and specificity of this assay, we next evaluated whether $\mathrm{RhB}-p$-SC $\mathrm{SC}_{6} \mathrm{~A}$-AuNPs could be used to screen AChE inhibitors. As indicated in Fig. 5, pretreated AChE
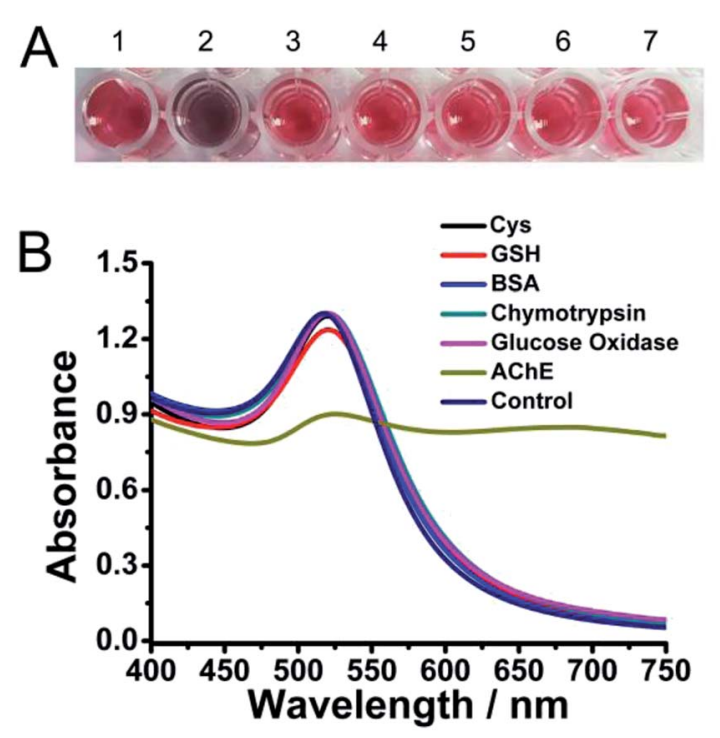

Fig. 4 Selectivity of the AChE sensor. (A) The color change of the solution in response to different species including biothiols and proteins that may exist in human body. (1) Control; (2) AChE; (3) Cys; (4) GSH; (5) BSA; (6) chymotrypsin; (7) glucose Oxidase. (B) Absorption curves of the solutions in (A). The final concentration of each biothiol was $0.1 \mathrm{mM}$ and the enzymes was $1 \mathrm{U} \mathrm{mL}-1$.

with tacrine, ${ }^{30,31}$ a well-known cholinesterase inhibitor, the aggregation of AuNPs was inhibited. The degree of AuNP aggregation was dependent on the concentration of tacrine. With the increase of tacrine concentrations, the colour of the solution changed from violet to wine red, corresponding to a decrease in $A_{600} / A_{520}$. The maximum inhibition ratio of tacrine was $89.63 \%$ with the $\mathrm{IC}_{50}$ value of $37.8 \mu \mathrm{M}$ (Fig. $5 \mathrm{~B}$ ), which was in accordance with the previous reports. ${ }^{30,31}$ Similarly, the further fluorescence recovery of $\mathrm{RhB}$ was blocked with the

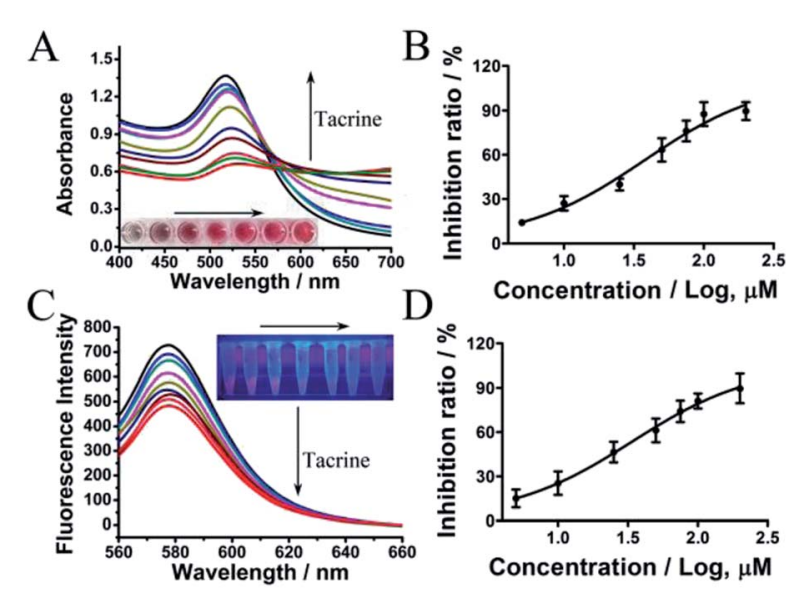

Fig. 5 The sensitivity of this assay for screening AChE inhibitors. (A) Absorbance spectra of the dispersion upon analyzing various concentrations of tacrine. (B) Calibration curve corresponding to inhibition ratio against the concentration of tacrine from colorimetric assay. (C) The fluorescence emission spectra of the dispersion upon analyzing various concentrations of tacrine. (D) Calibration curve corresponding to inhibition ratio against the concentration of tacrine from fluorescent assay. 

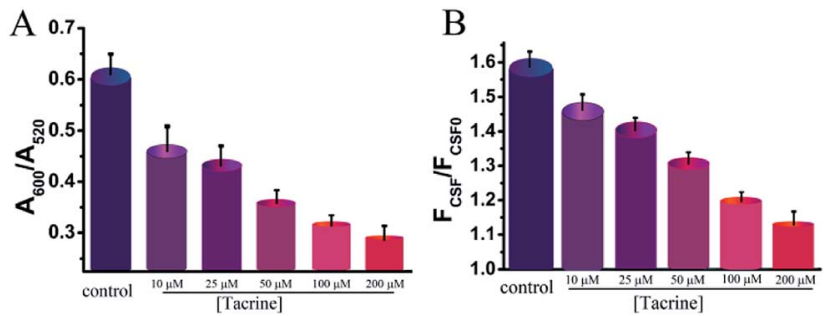

Fig. 6 Inhibition of CSF AChE activity by tacrine. (A) Absorption responses of the assay for CSF AChE activity pretreated with different concentrations of tacrine. (B) Fluorescence responses of the assay for the samples in (A).

increased concentration of tacrine, which was caused by the reduced amount of thiocholine fluorescence recovery of $\mathrm{RhB}$ (Fig. 5C). The $\mathrm{IC}_{50}$ value of tacrine obtained from the fluorescence method was $34.01 \mu \mathrm{M}$ (Fig. 5D), which was quite similar with that from the colorimetric assay. These results indicated that the two methods used to quantitate the inhibition of AChE in our assay showed no significant change in $\mathrm{IC}_{50}$ value. Our assay can be applied to screen AChE inhibitors and evaluate the inhibition efficiency.

\section{Analysis of CSF samples}

It was also necessary to determine whether our assay can be directly applied for monitoring AChE in real CSF samples. As shown in Fig. 6, addition of untreated CSF into the mixture of ATC and RhB- $p$-SC $\mathrm{SC}_{6} \mathrm{~A}$-AuNPs both induced the aggregation of AuNPs and recovered the fluorescence of the system. Furthermore, similar with the pure AChE samples, pretreated with different concentrations of tacrine, the CSF samples led to different degrees of AuNPs aggregation (Fig. 6). All these results revealed the practicality of using our method to determinate AChE levels and screen AChE inhibitors in real CSF samples, indicating its possibility for monitoring the disease progression and drug treatment effects for $\mathrm{AD}$.

\section{Conclusions}

In conclusion, based on the competitive host-guest interaction between $\mathrm{SC}_{6} \mathrm{~A}$-AuNPs and $\mathrm{RhB}$ /quaternary ammonium group, a highly sensitive and selective assay for AChE detection was successfully established. With the dual signal reporters, our system can differentiate well between AChE and other proteins with a detection limit as low as $0.16 \mathrm{mU} \mathrm{mL}^{-1}$. Furthermore, the present method was also successfully applied to determinate AChE levels and screen AChE inhibitors in real CSF samples, which was significantly important for monitoring the disease progression and drug treatment effects for AD. Crucially, when change RhB to AChE inhibitor, our system can also be used as $\mathrm{ACh}$ or choline responsive-drug release system. Given its simplicity and easy operation, this method may extend to highthroughput screening of AChE inhibitors and be highly useful in a wide range of applications such as drug discovery, bioanalysis, and targeted drug delivery system.

\section{Conflicts of interest}

There are no conflicts to declare.

\section{Acknowledgements}

The authors thank the financial supports from by the Youth Top-notch Talents Supporting Plan of Hebei Province (BJ2018007) and the Natural Science Foundation of Hebei Province (Grant No. H2017206214, H2016206280, H2016206096 and $\mathrm{H} 2017206281)$.

\section{Notes and references}

1 M. E. Hasselmo, Curr. Opin. Neurobiol., 2006, 16, 710-715.

2 S. Gais and J. Born, Proc. Natl. Acad. Sci. U. S. A., 2004, 101, 2140-2144.

3 F. Mangialasche, A. Solomon, B. Winblad, P. Mecocci and M. Kivipelto, Lancet Neurol., 2010, 9, 702-716.

4 P. Davidsson, K. Blennow, N. Andreasen, B. Eriksson, L. Minthon and C. Hesse, Neurosci. Lett., 2001, 300, 157-160.

5 N. C. Inestrosa, A. Alvarez, C. A. Pérez, R. D. Moreno, M. Vicente, C. Linker, O. I. Casanueva, C. Soto and J. Garrido, Neuron, 1996, 16, 881-891.

6 G. V. De Ferrari, M. A. Canales, I. Shin, L. M. Weiner, I. Silman and N. C. Inestrosa, Biochemistry, 2001, 40, 10447-10457.

7 M. G. Cottingham, M. S. Hollinshead and D. J. T. Vaux, Biochemistry, 2002, 41, 13539-13547.

8 J. Hou, Z. Tian, H. Xie, Q. Tian and S. Ai, Sens. Actuators, B, 2016, 232, 477-483.

9 G. L. Ellman, K. D. Courtney, V. Andres and R. M. Featherstone, Biochem. Pharmacol., 1961, 7, 88-90.

10 S. Hou, Z. Ou, Q. Chen and B. Wu, Biosens. Bioelectron., 2012, 33, 44-49.

11 P. Valeri, Y. Xiao and W. Itamar, Nano Lett., 2005, 5, 649-653.

12 Q. Liu, Y. Yang, H. Li, R. Zhu, Q. Shao, S. Yang and J. Xu, Biosens. Bioelectron., 2015, 64, 147-153.

13 L. Zhang, M. Chen, Y. Jiang, M. Chen, Y. Ding and Q. Liu, Sens. Actuators, B, 2017, 239, 28-35.

14 M. Chen, Y. Ding, Y. Gao, X. Zhu, P. Wang, Z. Shi and Q. Liu, RSC Adv., 2017, 7, 25220-25228.

15 A. Schena and K. Johnsson, Angew. Chem., 2014, 126, 13261329.

16 J. Chang, H. Li, T. Hou and F. Li, Biosens. Bioelectron., 2016, 86, 971-977.

17 X. Yan, Y. Song, X. Wu, C. Zhu, X. Su, D. Du and Y. Lin, Nanoscale, 2017, 9, 2317-2323.

18 P. Ni, Y. Sun, H. Dai, W. Lu, S. Jiang, Y. Wang, Z. Li and Z. Li, Sens. Actuators, B, 2017, 240, 1314-1320.

19 Y. Panraksa, W. Siangproh, T. Khampieng, O. Chailapakul and A. Apilux, Talanta, 2018, 178, 1017-1023.

20 H. D. Cancar, S. Soylemez, Y. Akpinar, M. Kesik, S. Göker, G. Gunbas, M. Volkan and L. Toppare, ACS Appl. Mater. Interfaces, 2016, 8, 8058-8067.

21 L. Saa, R. Grinyte, A. Sánchez-Iglesias, L. M. Liz-Marzán and V. Pavlov, ACS Appl. Mater. Interfaces, 2016, 8, 11139-11146. 
22 M. Wang, X. Gu, G. Zhang, D. Zhang and D. Zhu, Langmuir, 2009, 25, 2504-2507.

23 D. Liu, W. Chen, Y. Tian, S. He, W. Zheng, J. Sun, Z. Wang and X. Jiang, Adv. Healthcare Mater., 2012, 1, 90-95.

24 Q. Yao, B. Lü, C. Ji, Y. Cai and M. Yin, ACS Appl. Mater. Interfaces, 2017, 9, 36320-36326.

25 M. C. Yeung and V. W. Yam, Chem. Soc. Rev., 2015, 44, 41924202.

26 X. Zhou, X. Su, P. Pathak, R. Vik, B. Vinciguerra, L. Isaacs and J. Jayawickramarajah, J. Am. Chem. Soc., 2017, 139, 1391613921.
27 H. Huang, X. Yang, K. Wang, Q. Wang, Q. Guo, J. Huang, J. Liu, X. Guo, W. Li and L. He, Talanta, 2015, 144, 529-534.

28 D. Guo, V. D. Uzunova, X. Su, Y. Liu and W. M. Nau, Chem. Sci., 2011, 2, 1722-1734.

29 X. Wang, K. Koh and H. Chen, Sens. Actuators, B, 2017, 251, 869-876.

30 P. R. Carlier, D. Du, Y. Han, J. Liu and Y. Pang, Bioorg. Med. Chem. Lett., 1999, 9, 2335-2338.

31 M. I. Rodríguez-Franco, M. I. Fernández-Bachiller, C. Pérez, B. Hernández-Ledesma and B. Bartolomé, J. Med. Chem., 2006, 49, 459-462. 